\title{
A Research on the Integration Between ERP System and $\mathrm{ABCM}$
}

\author{
Ying He \\ School of Economics and Management, Beijing University of Post and \\ Telecommunications, Beijing 100876, P.R. China \\ Heyingcn2001@yahoo.com.cn
}

\begin{abstract}
In recent years, with the widespread application of ERP System, it creates an appropriate environment for implementing ABCM. Many enterprises produce the strong demands on the integration between ERP System and $A B C M$ which is process-focused. As a result, the integration of ERP System and $A B C M$ is regarded as an important strategic choice of fastening the step of information level by many enterprises. This paper mainly makes a detailed discussion on the possibility of the integration between ERP System and $A B C M$. It describes the benefits of the integration between ERP System and $A B C M$ and the relationship between ERP System and $A B C M$ in the process management. At last, it discusses the existing basic forms for the integration between ERP System and $A B C M$ from the perspective of theory and practice. A successful integration between ERP System and ABCM can minimize the costs of operation and maximize the Enterprise Value, while improving the quality of decision support information available to decision-makers within an organization.
\end{abstract}

Keywords: Activity-Based Costing $(A B C)$, Enterprise Resource Planning (ERP)

\section{INTRODUCTION}

From the perspective of the historical evolution of ERP, an important progress from MRP、MRP II 、 to ERP lies in realizing the same step of both finance system and produce system. It means the integration of cash flow and logistics. It is wellknown that the traditional procedures and accounting thoughts are run through in ERP system and the traditional cost accounting is designed in ERP system, the information generated from ERP system are distorted. They are hard to provide decision support information for strategic cost analysis such as value chains analysis vost performance analysis and so on. This discounts the function of ERP system. ABC is the most accurate cost accounting methods as yet. It may accurately measure the profitability on the product and the customer. It also may gain the cost information on the activity process and make aimed controls in order to make the internal supply chains more effective. $\mathrm{ABCM}$ can implement process excellent and process management by activity cost and cost drivers. This makes many enterprises produce the strong demands on the integration of ERP System and ABCM which is processfocused. As a result, the integration of ERP System and ABCM is regarded as an 
important strategic choice of fastening the step of information level by many enterprises.

\section{THE POSSIBILITY ANALYSIS ON THE INTEGRATION BETWEEN ERP SYSTEM AND ABCM}

\subsection{Unanimous ERP System and ABCM}

Although $\mathrm{ABC}$ comes from the veracity motivation of product cost calculation, its meaning has completely exceeded this level, and has gone deeply into the reconstruction on activity chain-value chain of the corporation, even involves the problem about the design of organization structure. Not all activities can create value in the activity chain of the corporation. The aims of $\mathrm{ABC}$ are customer chain-oriented, focusing on the activity chain and the value chain, reengineering 'the activity process' fundamentally and thoroughly, emphasizing how to coordinate the relationship between the customers in and out of the corporation, and the relationship among each department. Also, it requires the activities of materials supply, production and distribution coming into 'a activity process' continuously and synchronously, eliminating the activity that can't create value in the activity chain, making the corporation keep a state of continuous improvement, promoting the optimization of the value chain of the corporation, and establishing the competitive edge of the corporation in itself profession.

On the basis of manufacturing resource planning, the ERP System extends the scope of management, advances new construction, and integrates the customers' (include suppliers and distributors) demands out of the corporation with production operations in corporation organically, including the resources of the corporation. Regarding the process of the operation in the corporation as a chain (the activity chain in fact) that joined tightly is the essence of ERP System. ERP system has become popular in recent years because it typically integrates financial system, marketing system, production manufacturing system, quality control system, materials supply management system, human resource management system and so on using a relational database. The use of a relational database permits functional areas to share information without reentering the data or duplicating the data in databases throughout the organization[1]. The goal of ERP System is coordinating the resources in and out of the corporation and establishing the core competitive edge.

The demand of market brings activity and activity consumes resource, so the emergence of activity means the use of resource. In fact, the possible arrangements of activity through $\mathrm{ABCM}$ equivalents to the efficient arrangements of resource, thus corporation improves its activity efficiency means to advance the use efficiency of resource. 


\subsection{Enterprise Transfers from Traditional Cost Management to ABCM}

ERP is a kind of system which is composed of many plans, and the operation of the corporation which has implemented ERP system is controlled by all kinds of plans and management. The rationality of plans ensures the routine operation of ERP System. Because the precise data ensures the rationality of plans, the key of bringing ERP System into effect successfully is the accuracy of all kinds of data. However, it is usually anamorphic and tortuous of the production cost information provided by the ERP System basing on traditional cost calculation, and it will have a seriously effect on the manager to make the right estimation on the operation status of the corporation, especially for the corporation which the distribution cost takes a good proportion of production cost (telecommunications corporation etc.). Then, ERP System based on traditional cost management doesn't reveal the cost drivers, this makes the corporation can't recognize the causality of cost and control the cost effectively. At last, ERP System based on traditional cost management prevents the corporation from making the strategic cost analysis on value added, value chain, cost-benefit, etc., for its cost accounting method can't create working procedure and process cost information.

Seeing from the ABCM itself, it emphasizes the consolidation of pre-plan, control and feedback, which embodies fully the cost management method that includes the function of forecasting, decision, planning, controlling and analysis. So this method still stresses the function of the pre-estimation of standard cost, the analysis of cost difference after the real cost, and the responsibility cost management focusing on cost center. Therefore, it's necessary to integrate ERP System with ABCM for many corporations which pay more attention to the cost controlling.

\subsection{The Solid Technology Foundation for Successfully Putting ABCM in Practice}

The basic idea of ABCM sprouts in the 1930s', but it didn't come into peoples' notices until 1980s'. To the technology of the cost calculation, the difference between traditional costing and $\mathrm{ABC}$ is to use many distribution standards of the overhead expenses. Obviously, the complicated calculation of the production expenses would cause the cost exceeding the benefit without the rapid development and application of the ERP System, even in a environment that has possessed the technological base. the society base and the idea base. Thus, the activity costing will be difficult in putting into practice, but just an idea. The development and application of ERP System improves the ability of data collecting and arrangement of the corporation, and it establishes the technique base for the implementation of $A B C M$.

In a word, the integration between ERP System and ABCM has become the important choice for corporation to accelerate the information. On the basis of implementing ERP system, many corporations practice and apply ABCM, put their cost management procedure on the same data source, use a standard reporting system, realize the identical structure, all these applications enhance the operability of system. And it makes to control the cost and the benefit throughout all functional departments, 
which really improves the ability to control cost in the overall process of the corporation.

\section{THE BENEFITS OF INTEGRATION BETWEEN ERP SYSTEM AND ABCM AND THE RELATIONSHIP BETWEEN ERP SYSTEM AND ABCM IN THE PROCESS MANAGEMENT}

Baxendale[1-2] stated that ERP system can provides reliable activity cost-driver information by integrating production planning, materials management, and cost and management accounting in order to increase the accuracy of the product-cost information and to develop activity-based budgets(ABB). Brodeur[3] thought that integrating ERP System and $A B C M$ is to capitalize on the opportunity to improve the ongoing maintenance of the $A B C$ models, increase the likelihood that $A B C$ results will be utilized by decision-makers, and improve the design . implementation and early use of $A B C$ and ERP system. Altogether, the integration between ERP System and $A B C M$ will enable the view of value chain management and process management goes through into the operation level, and it is a major breakthrough in the management ideas. The integration is favorable to obtain the source, improve the efficiency of value chain management, and achieves the ultimate objective, which is maximizing the Enterprise Value. Figure 1 shows the position and relationship between ERP System and ABCM in the process management.

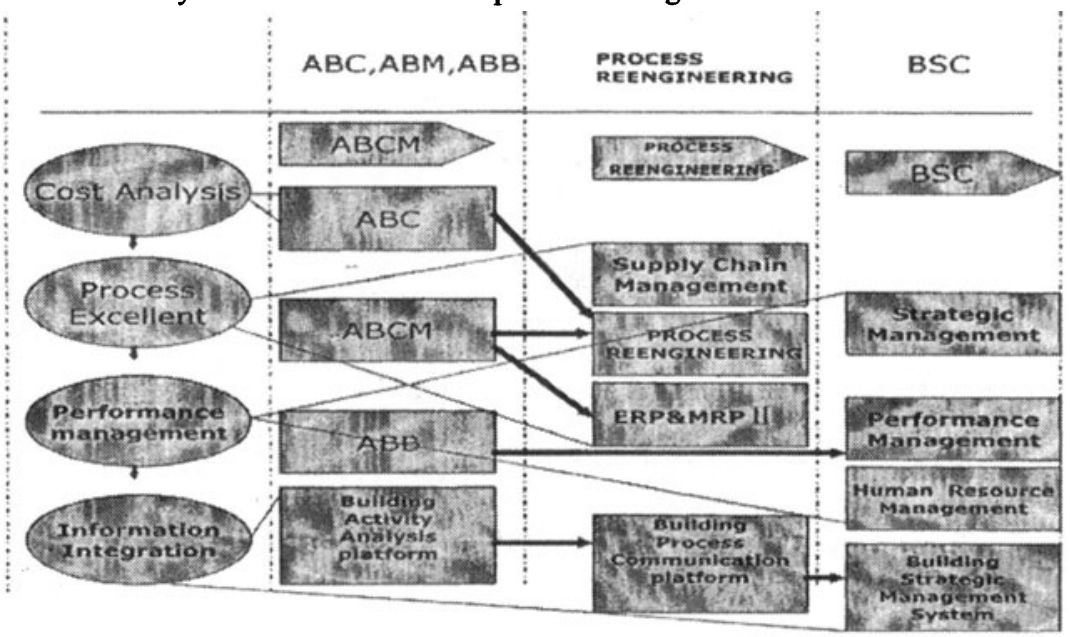

Figure 1. The Position and Relationship between ERP and ABCM in the Process Management 


\section{THE EXISTING BASIC FORMS FOR THE INTEGRATION BETWEEN ERP SYSTEM AND ABCM}

Theorists have different ideas on the existing basic forms for the integration between ERP System and ABCM. Some people states that ERP System and ABCM are two kinds of information systems, which are independent but related to each other. For example, in the discussion about ERP manufacturers and ABCM integration, Russell Shaw [4] considered that ERP System and ABCM are two stand-alone information systems, but maintains a relation of partnership. However, Brodeur [2] thought that ERP system could be used effectively by $\mathrm{ABCM}$ and $\mathrm{ABCM}$ could rapidly access a lot of non-financial data by ERP system, so the integration of them could promote their implementation(See Figure 2). Other people said that ABCM would be brought into each function-module completely after integrated. In other words, there were no independent sub-module to represent $\mathrm{ABCM}$ or was established by $\mathrm{ABCM}$, therefore, the essence of the integration for $\mathrm{ABCM}$ is to modify the function-module of ERP by using the concepts and methods of ABCM. Yaping Ning [5] considered that through integration, the technology and management ideas of $\mathrm{ABC}$ and $\mathrm{ABM}$ (part of $\mathrm{ABCM}$ ) are integrated to the ERP, which makes a few modules of $A B C M$ separate away from the original ERP. So to say, a few modules are created for $A B C M$, such as the sub-modules of activity-based accounting and activity efficiency analysis are added to the functional module of management accounting.

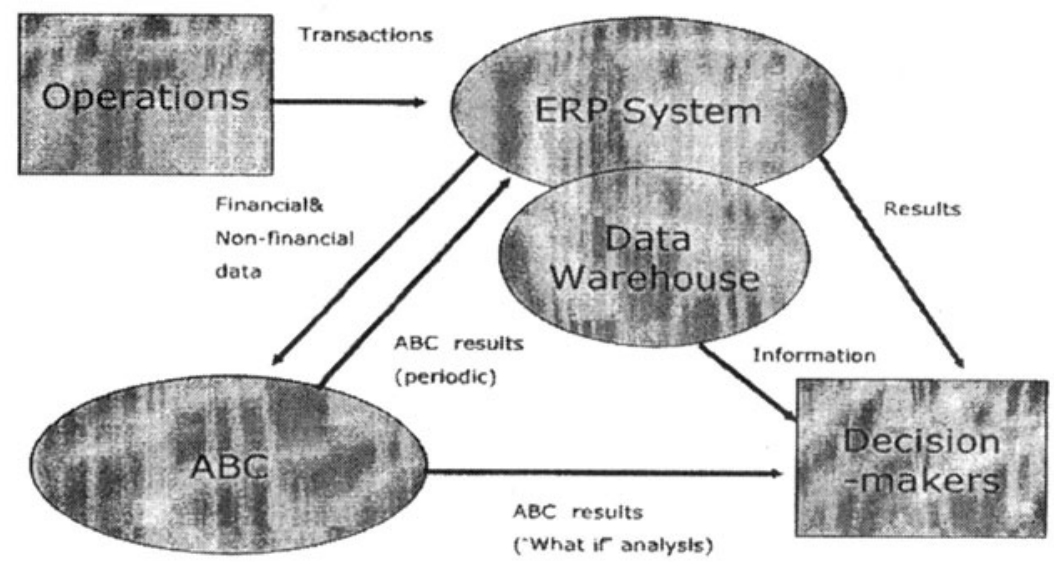

Figure 2. The Relationship between ERP System and ABC

In practice, a kind of special $\mathrm{ABCM}$ software which keeps a partnership between ERP system and $A B C M$, has become a key focus of many software developers. Many business management software suppliers all actively invest in this realm. And certainly there are also some companies, which add the function-modules of $\mathrm{ABCM}$ in the management systems of themselves(such as $\mathrm{ABCM}, \mathrm{SCM}$ etc.) in order to meet the needs of the customers in and out of the corporation. For example, SAS、ALG Software and QPR provide specialized ABCM software. In domestic, there are also 
some companies which are pushing forward the cost management system based on $\mathrm{ABCM}$, and start the tentative application and implementation in several professions.

In a word, as the ERP and the $\mathrm{ABCM}$ are both under developing in the theory and practice, so the existing basic forms for the integration between ERP System and $\mathrm{ABCM}$ will also be in the process of groping and optimizing.

\section{CONCLUSIONS}

Allocating the resource efficiently and manufacturing for making the needs of customers are the core concepts which ERP System and ABCM continuously pursue. The integration between ERP System and ABCM is to cancel the non-value added process and improve the value added process put to the best use in order to create more added values in the process management.

\section{REFERENCES}

1. S. Baxendale and F. Jama, What ERP can offer ABC, Strategic Finance. Volume 8, Number 1, pp.54-57, (2003).

2. S. Baxendale and P. Jokinen, Interactions between ERP and ABCM systems, Journal of Cost Management. Volume 3, Number 1, pp.40-46, (2000).

3. E. Brodeur, Integrating $\mathrm{ABC}$ and ERP systems, Focus Magazine. Volume 1, Number 1, pp.1-10, (2003).

4. R. Shaw, $\mathrm{ABC}$ and ERP: Partners at last?, Management Accounting. Volume 5, Number 1, pp.56-58, (1998).

5. Y. Ning, A study and analysis of the integration of ERP with ABCM, Financial and Accounting Communication. Volume 1, Number 1, pp.8-10, (2006).

6. Y. $\mathrm{Hu}, \mathrm{A}$ design on ERP and $\mathrm{ABC}$, Financial and Accounting Monthly. Volume 2, Number 1, pp.20-21, (2002). 